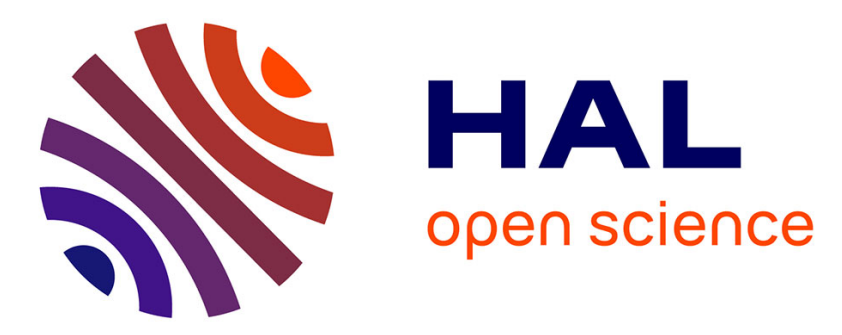

\title{
Optical properties of single magnetic quantum wells in an external magnetic field
}

S. Weston, T. Stirner, P. Harrison, J. Nicholls, W. Hagston, D. Ashenford

\section{To cite this version:}

S. Weston, T. Stirner, P. Harrison, J. Nicholls, W. Hagston, et al.. Optical properties of single magnetic quantum wells in an external magnetic field. Journal de Physique IV Proceedings, 1993, 03

(C5), pp.C5-397-C5-400. 10.1051/jp4:1993584 . jpa-00251671

\section{HAL Id: jpa-00251671 \\ https://hal.science/jpa-00251671}

Submitted on 1 Jan 1993

HAL is a multi-disciplinary open access archive for the deposit and dissemination of scientific research documents, whether they are published or not. The documents may come from teaching and research institutions in France or abroad, or from public or private research centers.
L'archive ouverte pluridisciplinaire HAL, est destinée au dépôt et à la diffusion de documents scientifiques de niveau recherche, publiés ou non, émanant des établissements d'enseignement et de recherche français ou étrangers, des laboratoires publics ou privés. 


\title{
Optical properties of single magnetic quantum wells in an external magnetic field
}

\author{
S. WESTON, T. STIRNER, P. HARRISON, J.E. NICHOLLS, W.E. HAGSTON and \\ D.E. ASHENFORD*
}

Department of Applied Physics, University of Hull. HU6 7RX, U.K.

* Engineering, Design and Manufacture, University of Hull. HU6 7RX, U.K.

\begin{abstract}
Photoluminescence measurement performed on magnetic $\mathrm{Cd}_{1-x} \mathrm{Mn}_{x} \mathrm{Te}$ quantum wells surrounded by $\mathrm{Cd}_{1-y} \mathrm{Mn}_{y} \mathrm{Te}$ barriers $(y>x)$, grown by M. B. E. and subjected to an external magnetic field, are described. The observed excitation spectra are shown to be in agreement with calculations of exciton energies based on the envelope function approximation.

Characteristic features of the samples are either the large ( $\sim 18 \mathrm{meV})$ Stokes' shift and/or the width of the P. L. lines $(\sim 11 \mathrm{meV})$. These are to be contrasted with the values in comparable non-magnetic wells of CdTe where the Stokes' shift is typically less than $1 \mathrm{meV}$ and the halfwidth of the P. L. lines is less than 1 or $2 \mathrm{meV}$. Arguments are presented which show that these observations, together with their magnetic field dependence, are consistent with the formation of magnetic polarons.

The photoluminescence emission also contains a band attributed to excitons bound to donors. It is observed experimentally that this donor-bound exciton emission disappears with increasing magnetic field. A theoretical interpretation of the observed properties of this band is given in terms of excitons bound to donors which are situated at different positions in the well and barrier region.
\end{abstract}

\section{Introduction}

The magneto-optical properties of non-magnetic wells, surrounded by magnetic barriers has received a great deal of attention in the literature, see for example Jackson et al[1] and references therein. However much less emphasis has been placed on investigations of the properties of magnetic wells, surrounded by magnetic barriers. The interest in magnetic systems arises in part, from the large carrier-magnetic ion exchange interaction resulting in a Zeeman splitting of the excitonic energy levels upto several tens of meV. This in turn is a useful probe for investigating the essential physics of such semiconductor heterostructures. Furthermore, the polarisation of the magnetic ions by a charge carrier can lead to the formation of magnetic polarons[3]. This not only has implications for the transport properties of the material but also acts as an important probe of the carrier dynamics and the fundamentals of the carrier-magnetic ion exchange interaction.

Quantum wells structures with magnetic wells and barriers, are of additional interest since they exhibit enhanced magneto-optical phenomena compared with non-magnetic systems. These enhancements arise from the presence of magnetic ions over the whole confined electron and hole regions. 


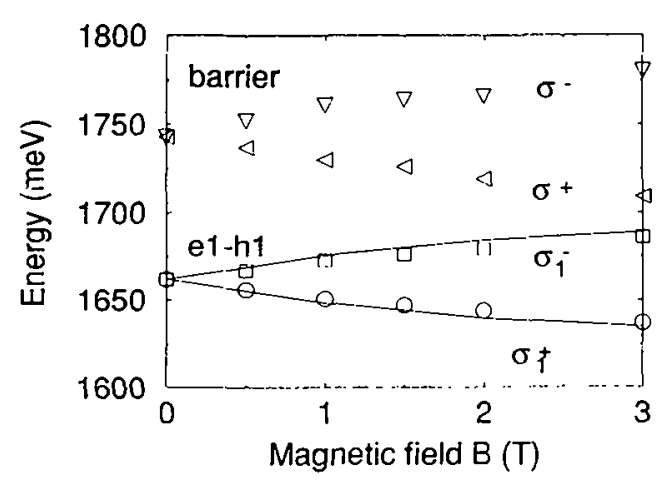

Figure 1: Magnetic field dependence of the P. L. E. of M405 together with theoretical predictions.

\section{Experimental details}

The CdMnTe samples were grown by M. B. E. on (001) InSb substrates followed by a $0.1 \mu \mathrm{m}$ buffer layer of CdTe[4]. One sample (M405) consisted of a $150 \AA$ well of $\mathrm{Cd}_{0.97} \mathrm{Mn}_{0.03} \mathrm{Te}$ surrounded by $200 \AA$ barriers of $\mathrm{Cd}_{0.90} \mathrm{Mn}_{0.10} \mathrm{Te}$. The second sample (M407) differs only with regard to the relative manganese concentrations, which are $y=0.29$ in the barrier and $x=0.11$ in the well.

Photoluminescence excitation (P. L. E.), photoluminescence emission (P. L.) and reflectivity measurements were performed at various external magnetic fields.

\section{Discussion and results}

Figure 1 shows the experimentally observed P. L. E. associated with the ground state electron (e1) and hole (h1), together with the barrier transitions, as a function of the applied external magnetic field for sample M405. The zero field position of the barrier excitation confirmed the manganese concentration as $y=0.097$. The solid lines show the theoretical fit obtained using the envelope function approximation [5] and a variational method $[6,7]$. The zero field energy position of the well transition is a sensitive function of the manganese concentration and this yielded a value of $x=0.035$. The magnitude of the Zeeman splitting of the el-hl well transitions was found to be dependent on the fractional offset in the valence band and this was consistent with a value of around $25 \%$. The enhancement of the Zeeman splitting is apparent when the measured (50meV) splitting at $3 \mathrm{~T}$, is compared with that calculated $(<1 \mathrm{meV})$, for a well of the same parameters but without manganese in the well.

As expected, sample M405 with a manganese concentration of only $3.5 \%$ in the well, shows little evidence of magnetic polaron formation, whereas sample M407 shows such evidence clearly. Figure 2(left) shows a modified Brillouin function fit [8] to the zero field reflectivity point and the higher field points of the P. L. data. Since magnetic field induced changes in confinement energies are small in such a wide well, the exciton energies follow essentially the varying bandgap of the $\mathrm{Cd}_{1-x} \mathrm{Mn}_{x} \mathrm{Te}^{\mathrm{N}}$ well material. The figure clearly shows a Stokes' shift between excitation and emission, of around $18 \mathrm{meV}$ at zero field, which is attributable to magnetic polaron formation, since contributions from interface disorder and exciton migration are expected to be negligible at wells of this width[9]. This value is considerably enhanced over that in the corresponding bulk material[10]. The magnetic field dependence of the Stokes' shift shown in Figure 2(right) is similar to that as measured for magnetic polarons by Yakovlev [3] via time resolved spectroscopy measurements. Similarly the magnetic field dependence of the emission linewidth is consistent with the results described by Gregory et al[10] 

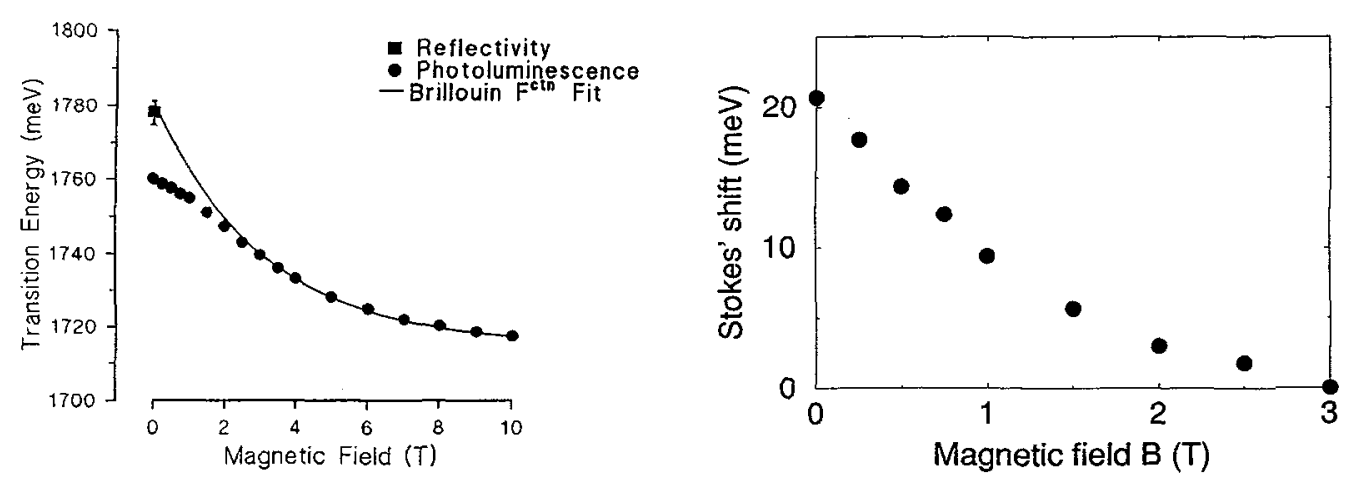

Figure 2: P. L. from M407 together with the zero field reflectivity point and a modified Brillouin function fit (left) and the magnetic field dependence of the Stoke's shift (right).

for polarons trapped at alloy fluctuations. It is clear that such experiments on magnetic quantum wells provide a convenient complementary route for investigating magnetic polaron effects in dilute magnetic semiconductors, to that offered by time resolved spectroscopy.
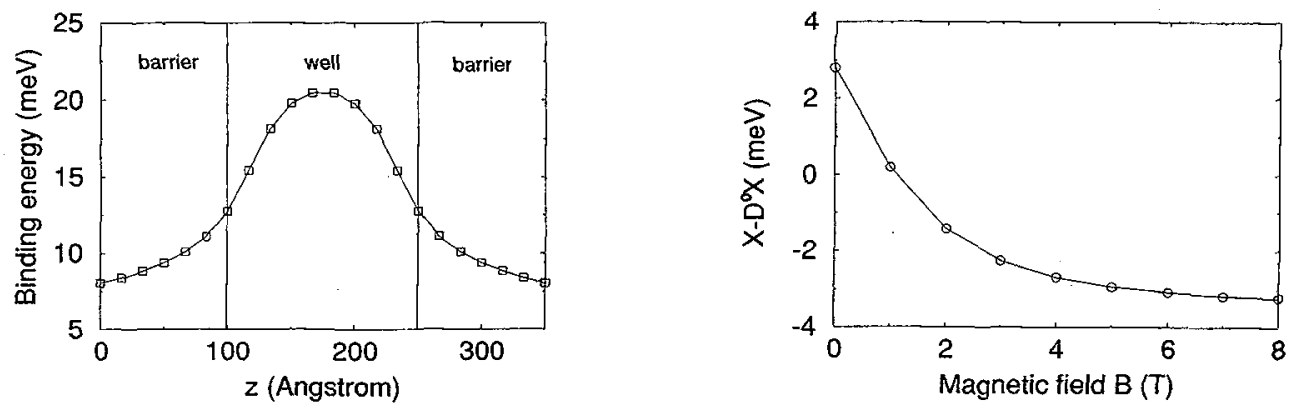

Figure 3: Neutral donor binding energy $E_{b}^{D^{0} X}$ as a function of donor position (left) and theoretically predicted free exciton $\mathrm{X}$-donor bound exciton $\mathrm{D}^{0} \mathrm{X}$ energy separation (right)

A characteristic feature of the P. L. from these and many other samples, is a double peak in the emission spectra. It is well known that the higher energy component of this peak can be assigned to 'free' excitons in the well region and that the lower energy component is associated with a neutral donor-bound exciton complex $\left(\mathrm{D}^{0} \mathrm{X}\right)$. The electrons of the bound exciton and the neutral donor form a spin pair, i.e. a Kramers doublet, which cannot be split by a magnetic field. Consequently when a magnetic field is applied to these systems a stage will eventually be reached when the energy of the bound $\left(\mathrm{D}^{0} \mathrm{X}\right)$ exciton is higher than that of the separate $\mathrm{D}^{0}$ and $\mathrm{X}$ complexes-i.e. the bound $\mathrm{D}^{0} \mathrm{X}$ system will become destabilised by the magnetic field[11]. What we wish to show is that our observations of this effect are consistent with a distribution of donors throughout the well and barrier region. Figure 3 shows the calculated[12] values of the binding energy of the electron to the neutral donor as a function of the position of the latter in the well and barrier regions, for sample M405. These same calculations also show that in M405 the donor binding energies are virtually independent of the magnetic fields upto $6 \mathrm{~T}$.

Utilizing the fact[13] that the exciton binding energy to the neutral donor $E_{b}^{D^{0} X}$ is a fraction of the neutral donor binding energy $E_{b}^{D^{0}}$, i.e. $E_{b}^{D^{0} X}=\xi E_{b}^{D^{0}}$ has enabled us to fit the zero field $D^{0} \mathrm{X}$ line, which peaked $\sim 2.8 \mathrm{meV}$ below the free exciton line $\mathrm{X}$, with a choice of $\xi=1 / 7$. Similarly the 
energy separation between the $\mathrm{X}$ and the $\mathrm{D}^{0} \mathrm{X}$ was calculated as a function of magnetic field and is shown in Figure 3(right).

It is apparent that at a field of around $1 \mathrm{~T}$ the free exciton energy falls below that of the donor bound exciton. The predicted resultant fall in intensity of the $\mathrm{D}^{\circ} \mathrm{X}$ emission relative to the $\mathrm{X}$ is consistent with experimental observations.

In non-magnetic quantum wells surrounded by magnetic barriers, the variation of the electron energy in a magnetic field is much reduced. Consequently the energy separation of the $\mathrm{X}$ and $\mathrm{D}^{0} \mathrm{X}$ emission lines is predicted to remain roughly constant, in agreement with observation.

\section{Conclusion}

It has been demonstrated that magnetic quantum wells, surrounded by magnetic barriers show enhanced Zeeman splitting of the excitonic transitions over non-magnetic wells. Comparison of the excitation and emission spectra have allowed the magnetic field dependence of magnetic polarons in a magnetic quantum well to be investigated.

Calculations have shown that the neutral donor binding energy as a function of donor position across a magnetic quantum well (M405) is not a sensitive function of magnetic field and comparison with experiment has given the binding energy of an exciton to a donor as $1 / 7$ of the neutral donor binding energy. Predictions of the energy destabilisation of the donor bound exciton and its subsequent disappearance from emission spectra in a magnetic field have been shown to be consistent with experimental observations.

\section{References}

[1]S. R. Jackson, J. E. Nicholls, W. E. Hagston, T. J. Gregory, P. Harrison, B. Lunn and D. E. Ashenford, Superlattices and Microstructures 12447 (1992)

[2]D. D. Awschalom, J. Warnock, J. M. Hong, L. L. Chang, M. B. Ketchen and W. J. Gallagher, Phys. Rev. Lett. 62199 (1989)

[3]D. R. Yakovlev and A. F. Ioffe, Festkörperprobleme, Advances in Solid State Physics 32 ed. by U. Rössler (Vieweg, Braunschweig/Weisbaden 1992), 251

[4]G. M. Williams, A. G. Cullis, C. R. Whitehouse, D. E. Ashenford and B. Lunn, Appl. Phys. Lett. 551303 (1989)

[5]G. A. Bastard. 'Wave Mechanics Applied to Heterostructures' Editions de Physique, Paris (1988)

[6]C. P. Hilton, W. E. Hagston and J. E. Nicholls. J. Phys. A 252395 (1992)

[7]C. P. Hilton, J. Goodwin, P. Harrison and W. E. Hagston. J. Phys. A 255365 (1992)

[8]J. A. Gaj, R. Planel and G. Fishman, Solid State Commun. 29435 (1979)

[9]W. E. Hagston, P. Harrison and T. Stirner, accepted for publication in Advanced Materials for Optics and Electronics.

[10]T. J. Gregory, C. P. Hilton, W. E. Hagston, J. E. Nicholls and J. J. Davies, Semicond. Sci. Technol. 7912 (1992)

[11]T. J. Gregory, J. E. Nicholls, J. J. Davies, J. O. Williams and N. Maung, Semicond. Sci. Technol. 31193 (1988)

[12]W. E. Hagston, P. Harrison and T. Stirner, to be published.

[13]Physics and Chemistry of II-VI compounds, ed. J. S. Prener and N. Aven, North-Holland Publishing Co. (1969) 